\title{
Mandibular growth activators and childhood OSAS
}

\author{
C. Chabre \\ Orthodontics specialist, former lecturer, Paris 7 University; former physician \\ at Pitié-Salpêtrière Hospital, Paris, France
}

ABSTRACT

Childhood OSAS mainly implicates hypertrophy of the lymphoid organs, but certain facial conditions such as maxillary endognathia and mandibular retrognathia are found in children with apnea and must be treated to restore respiratory function. The orthodontist should then use the most appropriate means to restore the maxillary transverse dimension and growth of the mandible. It is this last point that is dealt with here, discussing the role of growth activators in the treatment of retrognathia and their impact on the airways.

\section{KEYWORDS}

OSAS, mandibular retrognathia, growth activator

\section{INTRODUCTION}

According to Cohen Levy ${ }^{4}$, childhood OSAS is a clinically entity quite distinct from the adult form, with etiology predominantly featuring lymphoid organ hypertrophy, making adenotonsillectomy the first-line treatment attitude.

Guilleminault ${ }^{7}$, however, analyzed files for 400 children with apnea managed by adenotonsillectomy, and reported persistent sleep disordered breathing in $14.5 \%$ of cases, characterized by pharyngeal narrowing and maxillary hypertrophy and/or retromandibulism.

Although adenotonsillectomy is the first-line treatment, in case of endognathia and/or mandibular retrognathia orthopedic correction is mandatory. The present article focuses exclusively on management of retromandibulism.

\section{TREATMENT OF RETROMANDIBULISM}

In children, retromandibulism is managed in orthopedics, using growth activators, which modify the oral and facial environment and thus, via various mechanisms, contribute to correcting class II malocclusion.

Address for correspondence:

Claude Chabre - 19,

Rue Colbert - 92290 Chatenay-Malabry

France

e-mail: cl.chabre@free.fr
This is an Open Access article distributed under the terms of the Creative Commons Attribution License (http://creativecommons.org/licenses/by/4.0), which permits unrestricted use, distribution, and reproduction in any medium, provided the original work is properly cited.
Present-day activators are the direct descendents of Robin's monoblock and Andresen's activator. There are different types, which can be grouped together as rigid monoblocks, elastic activators and thrusting activators ${ }^{10}$.

Article received: 09-01-2015. Accepted for publication: 26-01-2015. 
In our own experience ${ }^{2,3}$, we use a monoblock activator to which we have associated an extra-oral force (Fig. 1).

Why associate an extra-oral force (EOF)? A major side-effect of activators is that they induce a clockwise maxillary and dental tilt and mandibular posterior rotation, impairing class II correction and increasing the vertical dimension. Associating EOF limits these side-effects by altering the resultant force pattern with respect to the maxillary and dental centers of resistance $^{10,2}$ (Fig. 2). Vertical control is improved and mandibular response is thereby optimized, freeing the oropharynx and thus facilitating breathing.

The effects to be expected with an activator and associated EOF are basically:

- dental-alveolar modifications;

- restricted maxillary growth;

- mandibular growth stimulation;

- and horizontal expression of the mandibular growth (Fig. 3).
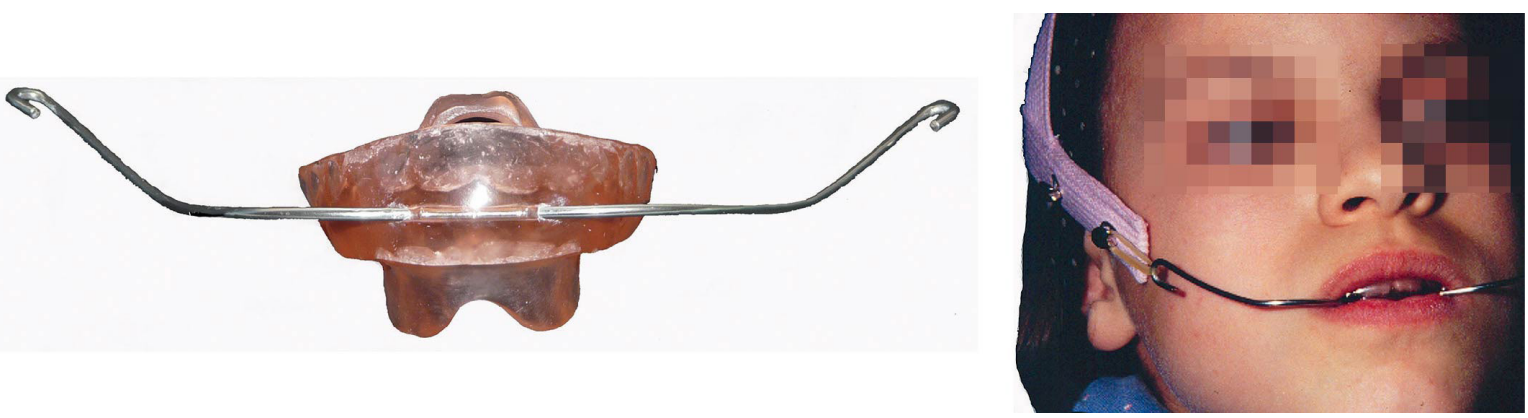

Figure 1

Association EOF + activator (Chabre).
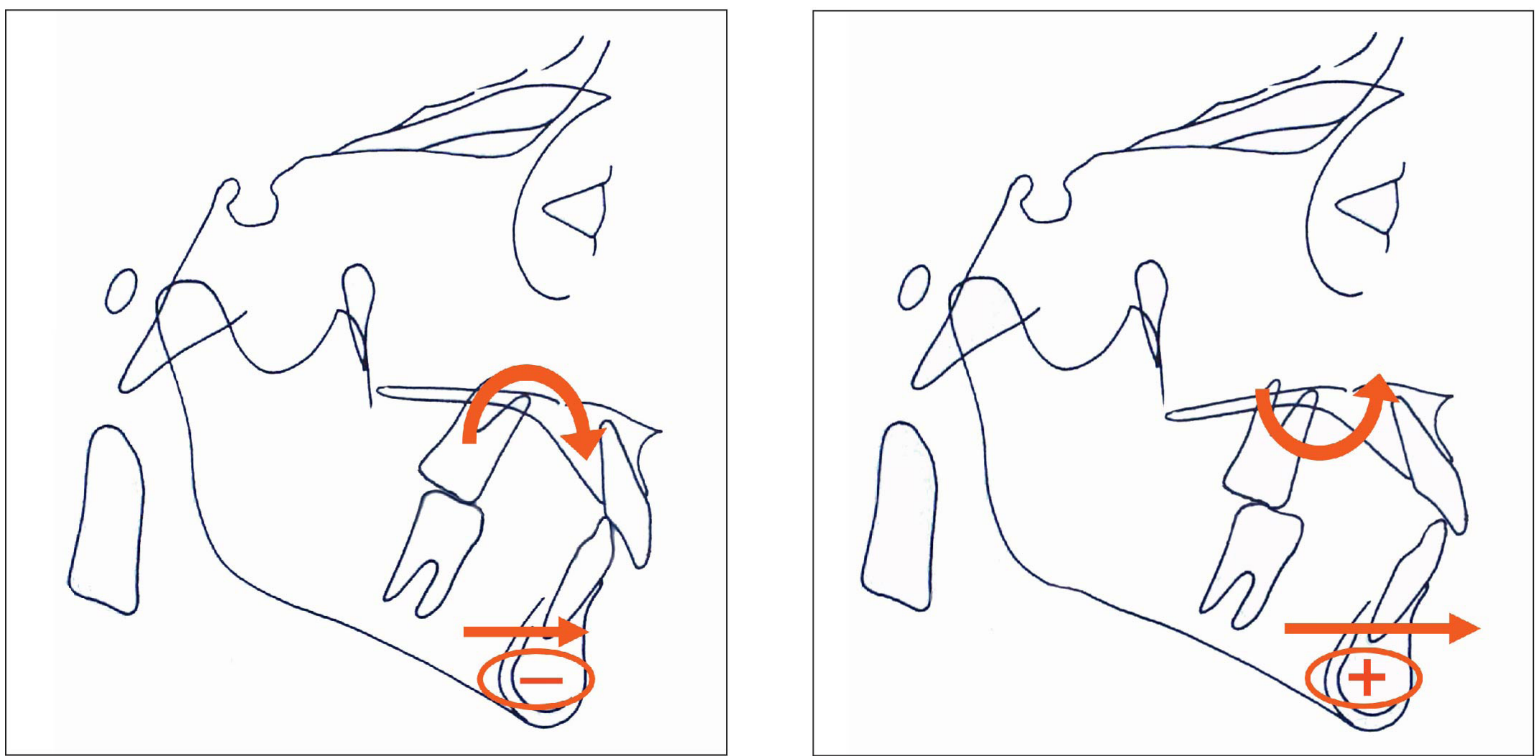

Figure 2

A single activator induces clockwise maxillary tilt (left), limiting mandibular advancement; adding an EOF with raised external branches induces anticlockwise tilt (right), enabling better mandibular response. 


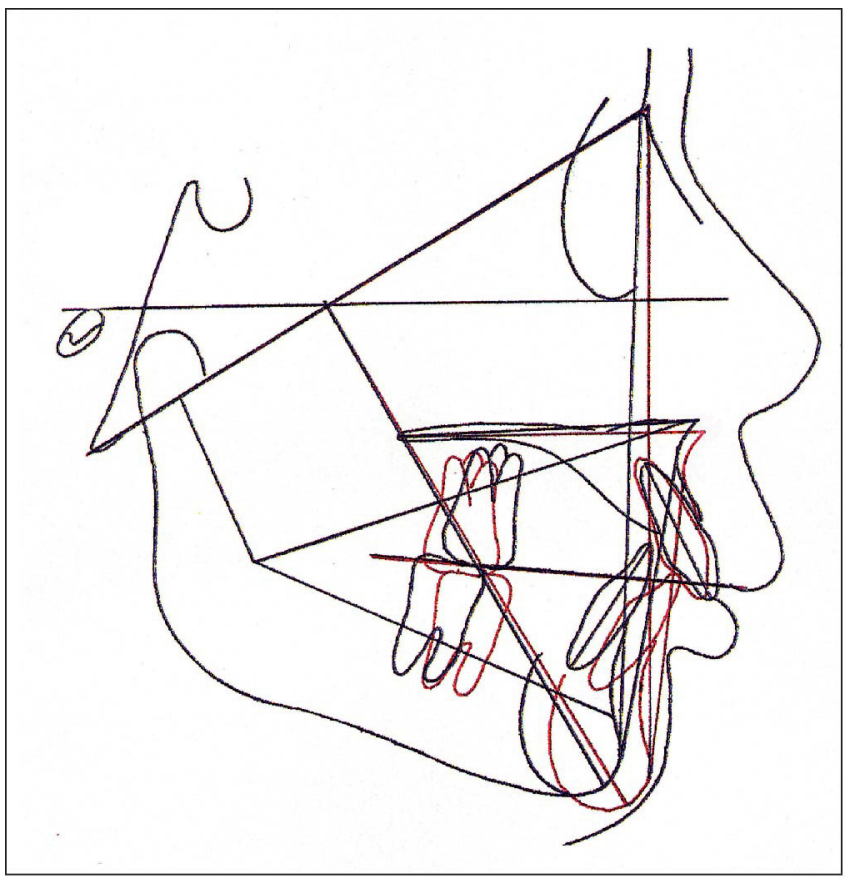

Figure 3

The impact of associating EOF to the activator were modeled in a study of 34 subjects (19 girls, 15 boys) aged 10 years 1 month \pm 13 months treated for $14.5 \pm 5.4$ months (M. Boulenguiez ${ }^{1}$.

\section{AUXOLOGIC POTENTIAL}

Clinical experience shows that not all mandibles have the same growth potential. Mandibles showing forward rotation on the Björk classification seem to show better growth response than those with backward rotation. Delaire ${ }^{5}$ assessed mandibular growth potential by morphologic analysis, comparing the area occupied by the ramus against optimal values: for ratios $>79 \%$, good growth response can be expected (Felpeto ${ }^{6}$ ).

Petrovic, Stutzmann and Lavergne ${ }^{9}$ determined mandibular auxologic potential on a decision tree combining biological data (bone renewal rate) and cephalometry (bone base position and rotational type).

\section{AIRWAY IMPACT OF RETROMANDIBULISM TREATMENT}

There are very few reports on the impact of treatment for retromandibulism on the airways. Comparing teleradiographs before and after growth activator treatment, it seems, quite subjectively, that the airway occupies a wider "area" after treatment (Fig. 4, 5 and 6). 

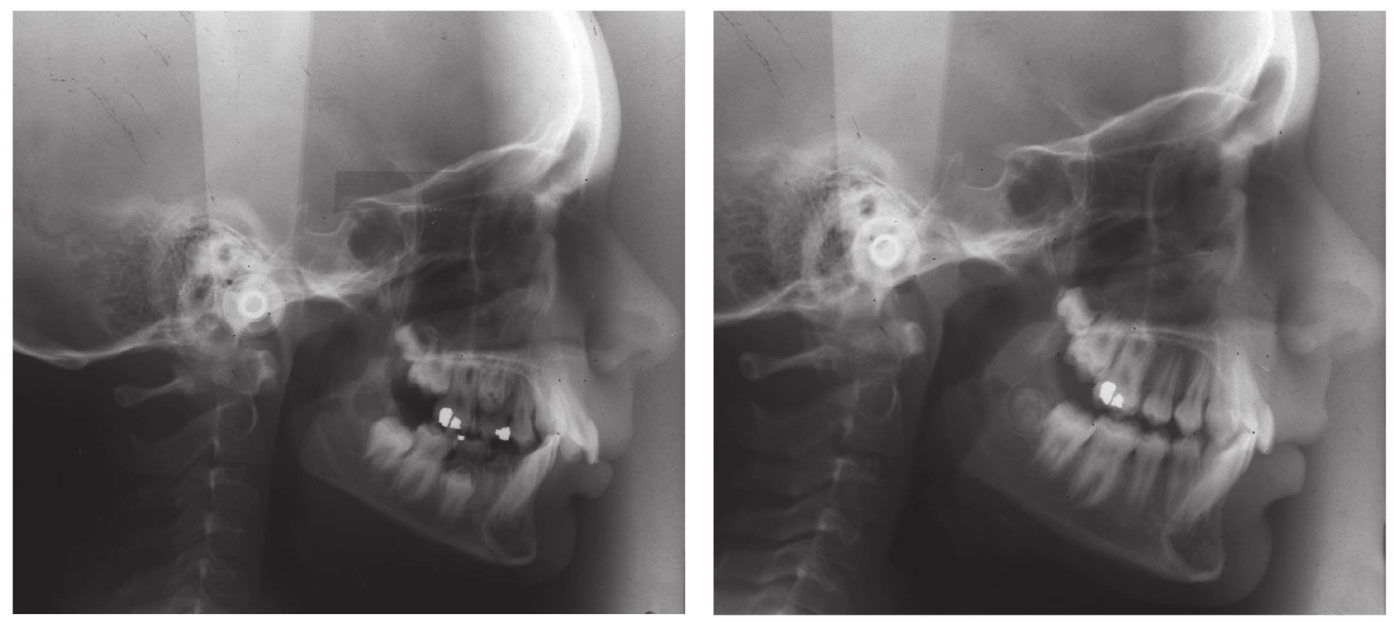

Figure 4

Jérôme S. before and after activator treatment.
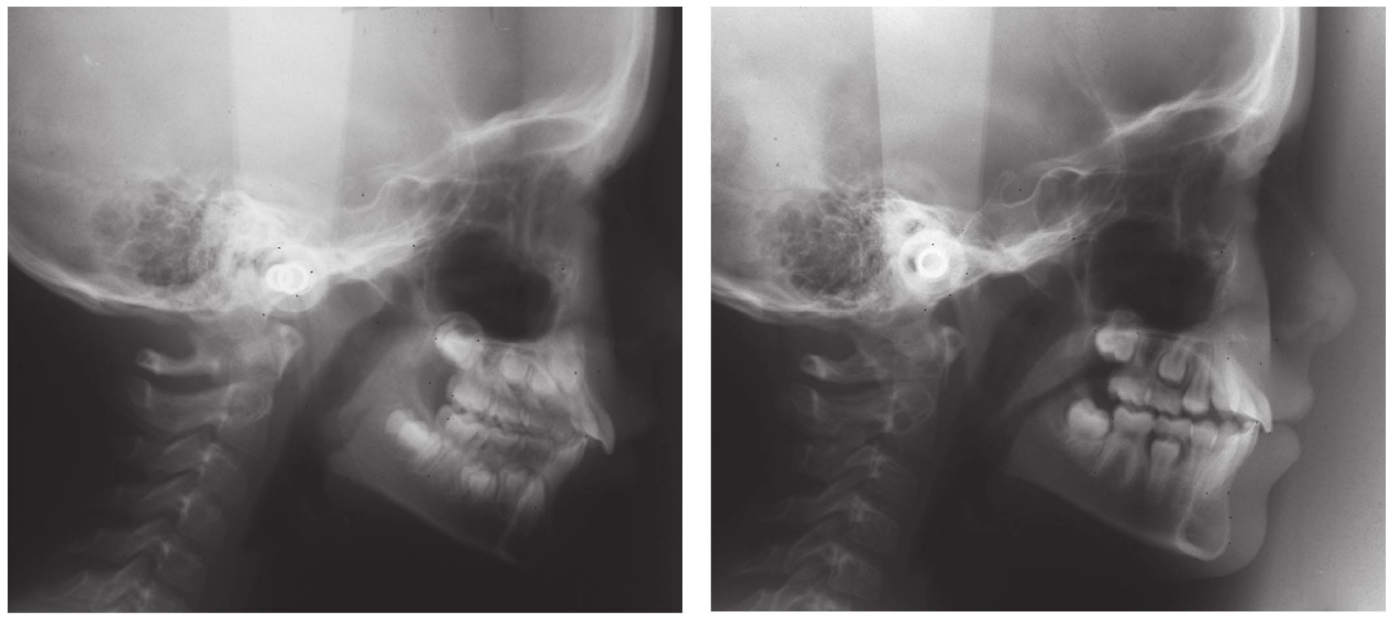

Figure 5

Mélanie $G$. before and after activator treatment

And "objectively"?

In 2010, Paluch's thesis ${ }^{8}$ studied variations in airway area on lateral radiographs in patients managed by activator versus controls.

"Results showed a highly significant difference ( $p=0.007$ ) in norma lateralis airway area growth between subjects treated by activators (+14\%) or not $(+8 \%)$, independently of gender, baseline typology or degree of propulsion applied."

But, does breathing improve with this norma lateralis airway area growth?

In 2012, Julia Cohen-Levy4, in her thesis, reported a randomized clinical study comparing 19 children (mean age, 6.86 years) treated using a mandibular advancement device for 6 

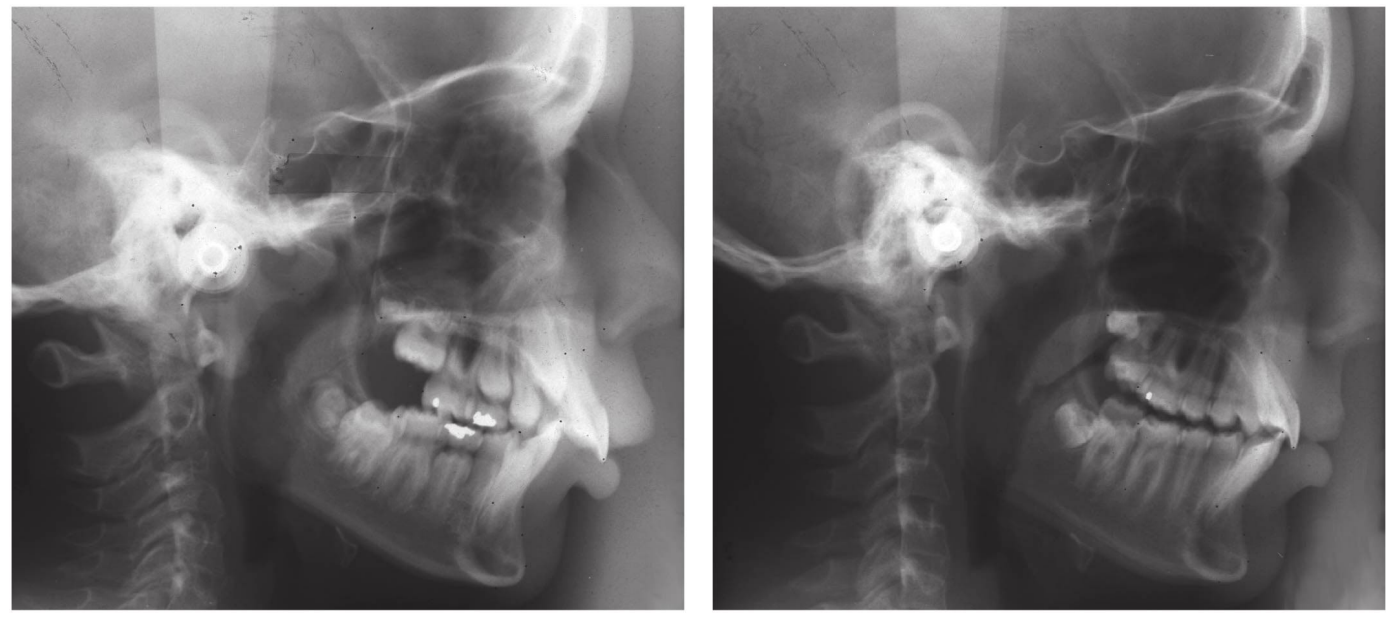

Figure 6

Arnauld $L$. before and after activator treatment.

months and 13 untreated control subjects (mean age, 7.34 years). Patients were assessed using a questionnaire, polysomnography and ENT and orthodontic clinical examination, but without X-ray or cephalometry, in line with US guidelines. At 6 months, AHI was significantly reduced in the treatment group ( $p=0.001$ ) and unchanged in controls. In $64.2 \%$ of the treatment group, AHI fell by at least $50 \%$, indicating treatment efficacy against OSAS, in parallel to correction of malocclusion.

Obviously, more thorough studies will be needed to confirm, refine or disprove these observations.

\section{CONCLUSION}

In children with retrognathia and OSAS, correction of retromandibulism by growth activator is an indispensable complement to adenotonsillectomy.

In children with retrognathia but free of OSAS, correction of retromandibulism by growth activator not only corrects arcade relations but may be considered as preventive of adult OSAS.

The objective is to free the orophar$y n x$ as well as possible, be the intention curative or preventive.

Conflict of interest: The author declares no conflict of interest.

\section{REFERENCES}

1. Boulenguiez M. Propositions d'objectifs visualisés pour les traitements orthopédiques associant activateur et force extra-orale. Mémoire CECSMO (directeur C. Chabre), Paris 7 University, 1994. 
2. Chabre C. Vertical control with a Head gear-Activator Combination. J Clin Orthod 1990;15:618-24.

3. Chabre C. Le préalable orthopédique dans le traitement des classes II. In: Lejoyeux E, Flageul F. Orthopédie dento-faciale : une approche bioprogressive. Quintescence Internationale, Paris 1999;81-103.

4. Cohen-Levy J. Avancée mandibulaire dans le syndrome d'apnées obstructives du sommeil : interactions avec l'orthopédie dento-faciale. PhD thesis, Pierre and Marie Curie University, 2012.

5. Delaire J. L'évaluation morphologique du potentiel de croissance de la mandibule : Les signes du turfiste. Orthod Fr 1995;66:465-78.

6. Felpeto B. Le potentiel auxologique mandibulaire, un indicateur pronostique du traitement orthopédique des classes II. CECSMO thesis, Paris 7 University, 2012.

7. Guilleminault C, Li KK, Khramstov A, Pelayo R, Martnez S. Sleep disordered breathing: surgical outcomes in prepubertal children. Laryngoscope 2004;14(1):132-7.

8. Paluch $\mathrm{C}$. Modifications des voies aériennes supé- rieures après traitement par activateur de Lautrou. Dental Surgery Doctoral thesis -Odontology Research Unit, Reims Champagne-Ardennes University, 2010.

9. Petrovic A, Lavergne J, Stutzmann J. Tissue-level growth and responsiveness potential: growth rotation and treatment décision. In: Vig P, Ribbens K. Science and clinical judgement in orthodontics. Monograph 19, pp. 181-223. Craniofacial growth series. University of Michigan. Ann Arbor 1986.

10. Simon Y, Chabre C, Lautrou A. Activateurs orthopédiques de croissance et malocclusion de classe II. Orthod Fr 2006;77:151-62. 